\title{
Immunophenotyping and oncogene amplifications in tumors of the papilla of Vater
}

\author{
Daniel Baumhoer • Inti Zlobec • Luigi Tornillo • \\ Wolfgang Dietmaier • Peter H. Wuensch • \\ Arndt Hartmann • Fausto Sessa • Petra Ruemmele • \\ Luigi M. Terracciano
}

Received: 27 June 2008 /Revised: 15 August 2008 / Accepted: 28 August 2008 / Published online: 21 October 2008

(C) Springer-Verlag 2008

\begin{abstract}
Carcinomas of the ampulla of Vater are rare and assumed to generally arise from preexisting adenomas (adenoma-carcinoma sequence). Histologically, distinct subtypes can be distinguished that were shown to differ significantly in terms of clinical outcome. Since pathologists usually receive bioptic tissue samples of ampullary tumors obtained during endoscopy, accurate classification of carcinoma subtypes can sometimes be difficult on morphological criteria alone. We therefore performed immunohistochemistry using a panel of established marker proteins (CK7, CK20, p21, p27, ESA, bax, and ephrin-B2) on 175 carcinoma, 111 adenoma, and 152 normal mucosa specimens of the ampulla of Vater and identified distinct immunoprofiles for every carcinoma subtype. Fluorescence
\end{abstract}

Petra Ruemmele and Luigi M. Terracciano shared senior authorship.

D. Baumhoer $(\bowtie) \cdot$ I. Zlobec $\cdot$ L. Tornillo $\cdot$ L. M. Terracciano

Institute of Pathology, University of Basel,

Schönbeinstrasse 40,

4003 Basel, Switzerland

e-mail: dbaumhoer@mac.com

W. Dietmaier • P. Ruemmele

Institute of Pathology, University of Regensburg,

Regensburg, Germany

P. H. Wuensch

Institute of Pathology, Municipal Hospitals of Nuremberg,

Nuremberg, Germany

A. Hartmann

Institute of Pathology, University of Erlangen,

Erlangen, Germany

F. Sessa

Anatomic Pathology Unit, Department of Human Morphology,

University of Insubria,

Varese, Italy in situ hybridization analyses of therapeutic target genes (c-myc, EGFR1, CCND1, HER2) found CCND1 to represent the most frequently amplified gene in our series $(7.5 \%)$.

Keywords Ampullary carcinoma · Papilla of Vater · FISH · TMA $\cdot$ Amplification $\cdot$ CCND1

\section{Introduction}

The papilla of Vater is a complex anatomical unit composed of highly specialized mucosa and musculature and represents the orifice of the pancreatic and bile duct within the duodenum. It contains the border between two completely different types of mucosa (intestinal mucosa of the duodenum and pancreatico-biliary duct mucosa) and regulates the flow of bile and pancreatic secretions with its sphincteric muscle (sphincter of Oddi) [1].

Tumors of the ampulla of Vater are rare, with an incidence of approximately 5.7 cases per million population per year, but are still more common than tumors of the rest of the small intestine [2-4]. Among periampullary tumors, they rank second after tumors of the pancreatic head and account for $6-20 \%$ of cases $[5,6]$. In $30-91 \%$ of ampullary carcinomas, residual adenomatous areas are detectable, indicating an adenoma-carcinoma sequence with stepwise accumulation of genetic alterations, similar to that observed in colorectal cancer [7, 8]. Due to the crucial function of the ampulla of Vater, neoplastic lesions early lead to an occlusion of the papillary orifice and therefore result in congestion of bile and pancreatic secretions. Patients generally present with obstructive jaundice, and histologic diagnosis can be achieved after biopsy during endoscopic retrograde cholangiopancreatography [9]. Early detection 
but also biologic differences are thought to be responsible for the better prognosis of ampullary tumors following pancreaticoduodenectomy compared to other periampullary tumors [10-12]. Concerning ampullary carcinomas, several surgical series have reported a median survival of 30 to 50 months and 5-year survival rates between $21 \%$ and $64 \%$ $[6,13-15]$.

The histopathology of ampullary carcinomas includes a broad spectrum of distinct subtypes, deriving from the different types of mucosa adjoining in the papilla of Vater $[3,5]$. According to the classification by the Armed Forces Institute of Pathology (AFIP), an intestinal type (IT), resembling carcinomas of intestinal origin, and a pancreatico-biliary type (PBT), resembling carcinomas of the extrahepatic bile ducts or the pancreas, are the most common subtypes and account for $70-95 \%$ of cases $[5,6$, 16-21]. Other subtypes include an intestinal-mucinous type (IMT), an invasive papillary type (IPT), a poorly differentiated adenocarcinoma (G3AC), and several rather uncommon entities [18]. Interestingly, the distinct subtypes were shown to differ significantly in cumulative survival, with IT demonstrating a mean survival of 76 months compared to 41 months in PBT (Ruemmele et al., submitted for publication). Since classification of ampullary tumors, particularly in bioptic material, can sometimes be difficult on histological criteria alone, we investigated 175 carcinoma, 111 adenoma, and 152 normal mucosa specimens of the papilla of Vater for their immunohistochemical expression of marker proteins commonly altered during carcinogenesis, including cytokeratins 7 and 20, cell cycle inhibitors p21 and p27, epithelium-specific intercellular adhesion molecule [epithelial specific antigen (ESA)], promoter of apoptosis bax, and regulator of angiogenesis ephrin-B2, and created immunoprofiles of the distinct subtypes. Additionally, fluorescence in situ hybridization (FISH) analyses were performed to determine whether known oncogenes, that can serve as potential target genes for current or future gene-specific therapies (c-myc, EGFR1, CCND1, HER2), participate in genomic rearrangements and could therefore be of clinical significance in ampullary carcinoma.

\section{Materials and methods}

Tissue samples and patient characteristics

The files of the Institute of Pathology, University Hospital Basel (Switzerland), the Institute of Pathology, University of Regensburg (Germany), the Institute of Pathology Nuernberg, and the Anatomic Pathology Unit, Department of Human Morphology, University of Insubria, Varese (Italy) were searched for adenomas or carcinomas of the ampulla of Vater over the period from 1985 to 2005 . In total, 175 carcinoma, 111 adenoma, and 152 normal mucosa samples were retrieved. Sufficient paraffin-embedded tissue for tissue microarray (TMA) construction was available in all cases. The male-to-female ratio was 3:2; mean age at diagnosis was 63 years (range 15-81 years).

\section{TMA construction}

Tissue samples were fixed in buffered $4 \%$ formalin, embedded in paraffin, and used to construct a TMA. Briefly, hematoxylin-eosin (H\&E)-stained sections were made from each selected primary block (donor blocks) to define representative tissue regions. Tissue cylinders $(0.6 \mathrm{~mm}$ in diameter) were then punched from the region of the donor block with the use of a custom-made precision instrument (Beecher Instruments, Silver Spring, USA). Tissue cylinders were transferred to a $25 \times 35 \mathrm{~mm}$ paraffin block to produce the TMA block used for the study. The resulting TMA block was cut into $3 \mu \mathrm{m}$ sections that were transferred to glass slides by use of the Paraffin Sectioning Aid System (Instrumedics, Hackensack, USA). Sections from the TMA block were used for immunohistochemistry. The number of punches per patient ranged from one to three for both normal tissue and carcinoma and from one to five for patients with adenomas. One punch was collected per patient on average (median 1.0) for each of the tissue types.

\section{Histology and immunophenotyping}

All tissue samples were reviewed by two experienced surgical pathologists (P.R. and L.M.T.) based exclusively on $\mathrm{H} \& \mathrm{E}$ staining. Carcinomas were subclassified according to the criteria published by the AFIP [18]. Tumors essentially indistinguishable from colorectal carcinomas were classified as intestinal types, whereas carcinomas showing a dense desmoplastic stroma surrounding small glands or solid nests of tumor cells were referred to as the pancreaticobiliary subtype. Invasive papillary carcinomas typically formed papillary and micropapillary structures in their invasive component, and poorly differentiated adenocarcinomas lacked histologic features of glandular or other differentiation. Additionally, an intestinal-mucinous subtype, characterized by any mucinous differentiation, was defined. Characteristics of antibodies are listed in Table 1.

Evaluation of immunohistochemistry

Immunoreactivity for each protein marker was scored semiquantitatively by evaluating the number of positive tumor cells over the total number of tumor cells. Scores were assigned using 5\% intervals and ranged from $0 \%$ to $100 \%$. 
Table 1 Characteristics of antibodies

\begin{tabular}{llll}
\hline Antibody & Dilution & Detection & Manufacturer \\
\hline CK7 & $1: 200$ & Bond & Dako Cytomation \\
CK20 & $1: 50$ & Bond & Dako Cytomation \\
p21 & $1: 25$ & Bond & Dako Cytomation \\
p27 & $1: 200$ & Bond & Dako Cytomation \\
ESA & $1: 200$ & Bond & Novocastra \\
bax & $1: 100$ & Bond & Neomarkers \\
ephrin-B2 & $1: 200$ & ABC & R\&D Systems \\
\hline
\end{tabular}

ESA epithelial specific antigen, Bond Bond Vision Biosystems, $A B C$ avidin-biotin-peroxidase-complex

The reproducibility of this scoring method between pathologists has previously been demonstrated for TMAs $[22,23]$. In order to select the cut-off score for protein marker positivity, receiver operating characteristic curve (ROC) analysis was performed [24]. Using this method, the sensitivity and 1-specificity of the protein marker for the outcome at each protein expression score is plotted, thus generating the ROC curve. The $(0,1$ criterion) was used to identify the point on the curve maximizing the sensitivity and specificity for the outcome and thereby having the shortest distance to the coordinate $(0,1)$. The protein expression score corresponding to this point was thus selected as the threshold value above which a tumor was considered "positive".

Fluorescence in situ hybridization

Five-micrometer sections of the TMA were made and treated according to the paraffin pretreatment reagent kit protocol before hybridization (Vysis, IL, USA). SpectrumOrange-labelled gene-specific probes were used together with SpectrumGreen-labelled probes for the respective centromere as a reference. The probe combinations were: c-myc/centromere 8 (Vysis), EGFR1/centromere, 7 (Vysis) CCND1/centromere 11 (Vysis), and HER2/centromere 17 (Vysis). Hybridization was performed according to the manufacturer's instructions (Vysis). Tumors were considered amplified if the ratio between oncogene and corresponding centromere was $>2.0$. Polysomy on the other hand was defined as more than two oncogene and centromere copies per nucleus without an increase in the ratio between oncogene and corresponding centromere.

\section{Statistical analyses}

Differences in negative and positive expression between tumor types were evaluated by the chi-square test. The predictive and independent value of the immunohistochemical markers to discriminate between tumor types was carried out by univariate and multiple logistic regression analysis. The odds ratio (OR), 95\% CI, and $p$ values were used to determine the effect of each marker on outcome. All analyses were carried out using SAS V9 (The SAS Institute, Cary, NC, USA), and $p$ values $<0.05$ were considered statistically significant.

\section{Results}

Histologic classification of ampullary carcinomas

Classification of 175 ampullary carcinomas investigated in our series identified 85 intestinal types, 42 pancreaticobiliary types, 23 poorly differentiated adenocarcinomas, 16 intestinal-mucinous types, and nine invasive papillary types (Fig. 1).

Grading of adenomas and association to carcinoma subtypes

Histologic grading was evaluable in 76 of $111(68 \%)$ adenomas of our series and disclosed low-grade dysplasia in 57 of $76(75 \%)$ and high-grade dysplasia in 19 of 76 $(25 \%)$ cases. All adenomas demonstrated tubular or tubulovillous architecture. Seventy-eight of $111(70 \%)$ adenoma samples were derived from patients suffering from coexisting carcinoma. The corresponding subtypes were 49 IT, 13 IMT, 8 PBT, 6 G3AC, and 2 IPT.

Immunophenotyping of ampullary carcinomas, adenomas, and normal mucosa

The immunoprofiles of all investigated carcinoma, adenoma, and normal mucosa samples are shown in Table 2 and Fig. 2, respectively. The most discriminating results were demonstrated for CK7 and bax. Whereas normal, premalignant and malignant tissue samples stained increasingly positive for CK7 $(2.6 \%, 12.8 \%$, and $44.7 \%)$, bax revealed an opposite trend $(55.6 \%, 64.3 \%$, and $37.6 \%)$. Additionally, p21 and p27 showed significant differences in their expression values between the three groups.

Immunophenotyping of ampullary carcinoma subtypes

Of the eight immunohistochemical marker proteins investigated, CK7 $(p<0.001), \mathrm{p} 27(p=0.012)$, ESA $(p=0.038)$, and bax $(p<0.001)$ expression demonstrated significant differences among the tumor types (Table 3 and Fig. 3). More than $75 \%$ of PBT and $72.2 \%$ of G3AC showed no expression of bax, while $92.3 \%$ of IMT were negative for CK7. IT stained negative for CK7 in $67.5 \%$ of cases and were never positive for $\mathrm{CK} 7, \mathrm{p} 27$, and ESA and negative 

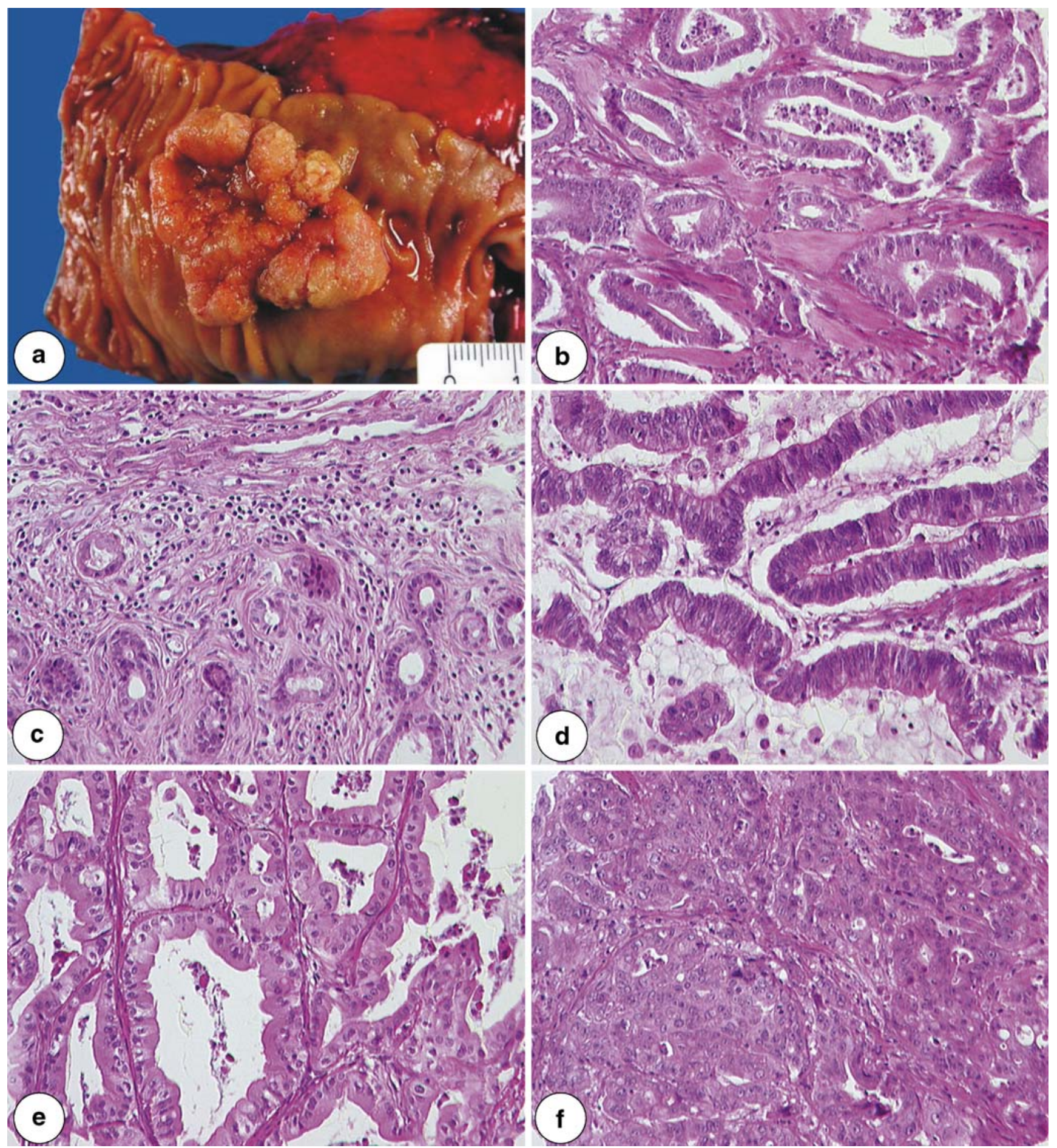

Fig. 1 Gross findings of an ampullary carcinoma showing a sessile exophytic tumor at the ampullary orifice (a). Histologic findings of ampullary carcinoma subtypes: IT (b), PBT (c), IMT (d), IPT (e), and G3AC (f) $(\mathrm{H} \& \mathrm{E} \times 400)$

for bax simultaneously. The association of p27, ESA, bax, and CK7 were evaluated in univariate and multivariable analysis in order to establish immunophenotypes specific for each tumor subtype. Findings are summarized in Fig. 4.
CK7 negativity $[p=0.002 ; \mathrm{OR}=0.37(0.2-0.7)]$ and positivity of bax $[p=0.003 ; \mathrm{OR}=2.76(0.4-5.4)], \mathrm{p} 27[p=$ $0.044 ; \mathrm{OR}=2.0(1.2-4.2)]$ and ESA $[p=0.012 ; \mathrm{OR}=2.3$ (1.2-4.2)] were significantly associated with the IT tumor type. Multivariable analysis demonstrated, however, that 
Table 2 Immunoprofiles of normal mucosa, adenoma, and carcinoma tissue samples

\begin{tabular}{|c|c|c|c|c|c|c|}
\hline \multirow[t]{2}{*}{ Protein } & \multirow[t]{2}{*}{ Expression } & \multirow[t]{2}{*}{ Cutoff (\%) } & \multicolumn{3}{|c|}{ Histologic type } & \multirow[t]{2}{*}{$p$ value } \\
\hline & & & $\begin{array}{l}\text { Normal } \\
N=152\end{array}$ & $\begin{array}{l}\text { Adenoma } \\
N=111\end{array}$ & $\begin{array}{l}\text { Carcinoma } \\
N=175\end{array}$ & \\
\hline \multirow[t]{4}{*}{ CK7 } & & 80 & & & & \\
\hline & Negative & & $113(97.4)$ & $82(87.2)$ & $89(55.3)$ & \multirow{3}{*}{$<0.001^{*}$} \\
\hline & & & & & & \\
\hline & Positive & & $3(2.6)$ & $12(12.8)$ & $72(44.7)$ & \\
\hline \multirow[t]{4}{*}{ CK20 } & & 50 & & & & \\
\hline & Negative & & $58(46.4)$ & $52(53.6)$ & $76(47.5)$ & \multirow{3}{*}{0.524} \\
\hline & & & & & & \\
\hline & Positive & & $67(53.6)$ & $45(46.4)$ & $84(52.5)$ & \\
\hline \multirow[t]{4}{*}{ p21 } & & 0 & & & & \\
\hline & Negative & & $90(74.4)$ & $61(62.9)$ & $96(59.6)$ & \multirow{3}{*}{$0.031 * *$} \\
\hline & & & & & & \\
\hline & Positive & & $31(25.6)$ & $36(37.1)$ & $65(40.4)$ & \\
\hline \multirow[t]{4}{*}{ p27 } & & 5 & & & & \multirow{4}{*}{$0.002 * * *$} \\
\hline & Negative & & $39(32.5)$ & $33(35.5)$ & $75(52.8)$ & \\
\hline & & & & & & \\
\hline & Positive & & $81(67.5)$ & $60(64.5)$ & $67(47.2)$ & \\
\hline \multirow[t]{4}{*}{ ESA } & & 90 & & & & \multirow{4}{*}{0.874} \\
\hline & Negative & & $63(50.4)$ & $51(52.0)$ & 78 (48.7) & \\
\hline & & & & & & \\
\hline & Positive & & $62(49.6)$ & $47(48.0)$ & $82(51.3)$ & \\
\hline \multirow[t]{4}{*}{ bax } & & 10 & & & & \multirow{4}{*}{$<0.001 * * * *$} \\
\hline & Negative & & $51(44.4)$ & $30(35.7)$ & $93(62.4)$ & \\
\hline & & & & & & \\
\hline & Positive & & $64(55.6)$ & $54(64.3)$ & $56(37.6)$ & \\
\hline \multirow[t]{3}{*}{ ephB2 } & & 75 & & & & \multirow[b]{3}{*}{0.058} \\
\hline & Negative & & $76(65.5)$ & $48(62.3)$ & $72(51.4)$ & \\
\hline & Positive & & $40(34.5)$ & $29(37.7)$ & $68(48.6)$ & \\
\hline
\end{tabular}

* Significant difference between normal and adenoma $(p<0.001)$ and normal and carcinoma $(p<0.001)$

**Significant difference between normal and carcinoma $(p=0.01)$

$* * *$ Significant difference between normal and carcinoma $(p=0.001)$ and adenoma and carcinoma $(p=0.009)$

$* * * *$ Significant difference between normal and carcinoma $(p=0.004)$ and adenoma and carcinoma $(p<0.001)$

only CK7 $(p<0.001)$ and bax $(p<0.001)$ were independent predictors of this phenotype and useful in the discrimination of IT from other tumors (sensitivity 0.69 , specificity 0.58 ).

In contrast, CK7 positivity $[p<0.001 ; \mathrm{OR}=5.03(2.2-$ $11.3)]$ and absence of bax $[p<0.001 ; \mathrm{OR}=0.22(0.1-0.5)]$, p27 $[p=0.001 ; \mathrm{OR}=0.22(0.1-0.6)]$, and ESA $[p=0.004$; $\mathrm{OR}=0.31(0.1-0.7)]$ were significantly associated with the PBT tumor type compared to the remaining subtypes. CK7, bax, and p27 were independently predictive $(p<0.001)$ of PBT (sensitivity 0.92 , specificity 0.48 ).

The discrimination of IMT tumors could be best performed by assessing CK7. Absence of CK7 [ $p=0.023$; $\mathrm{OR}=0.09(0.01-0.7)]$ expression was very strongly predictive of IMT and was the only marker found to discriminate IMT from the remaining tumor types (sensitivity 0.87 , specificity 0.65 ).
None of the immunohistochemical markers were significantly predictive of either G3AC or IPT.

FISH analyses

The results of the FISH analyses are presented in Table 4. The number of evaluable cases varied between different FISH probes due to insufficient hybridization, absence of unequivocal tumor cells in the arrayed tissue, as well as lack of tissue on serial sections of the array. CCND1 showed the highest amplification frequency among the analyzed genes (two of 74 adenomas and ten of 134 carcinomas) in our series, whereas c-myc, EGFR, and HER2 were amplified only infrequently. There were no associations between gene amplifications and distinct histologic subtypes of ampullary carcinomas. 


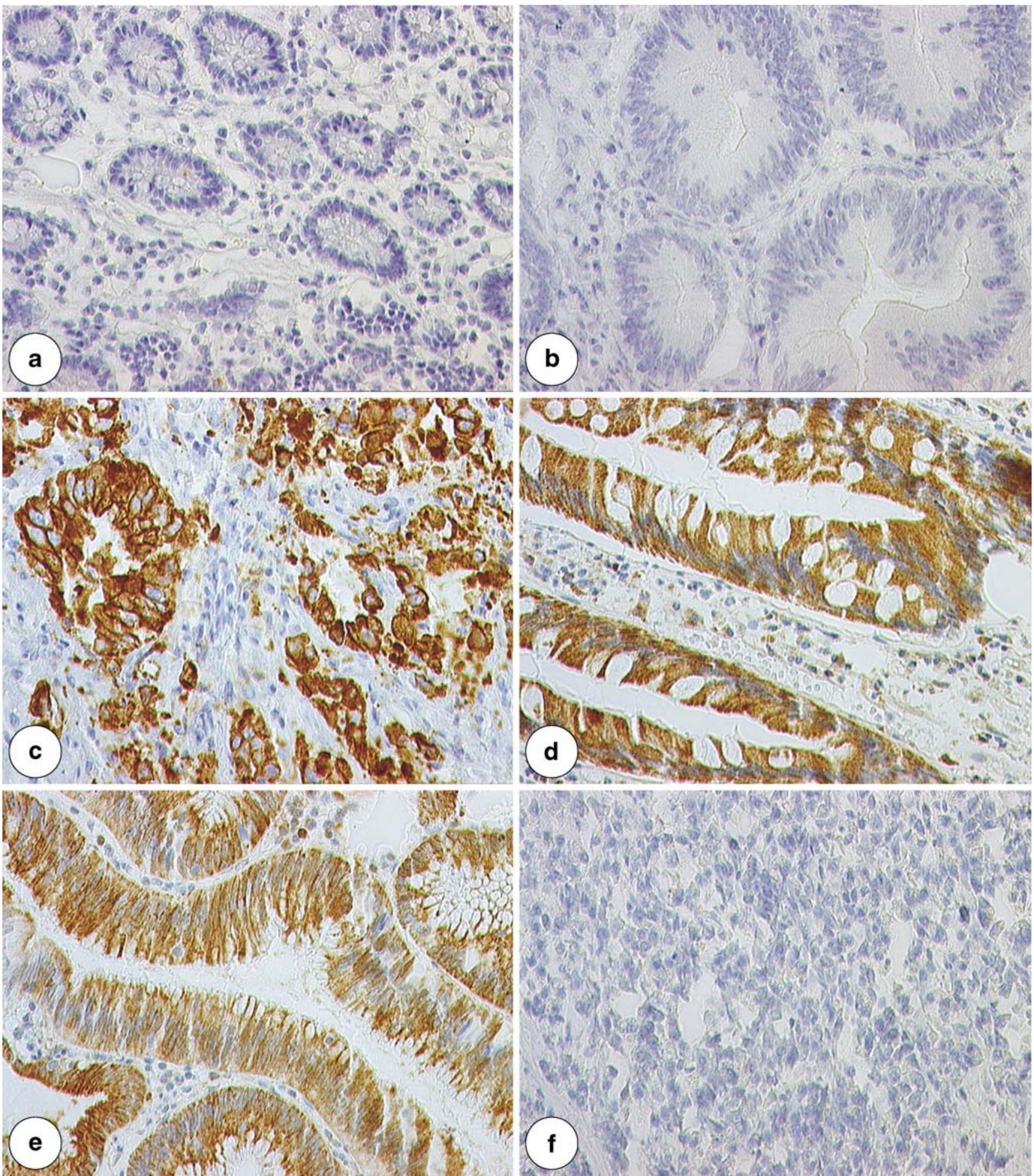

Fig. 2 CK7/bax immunostaining in normal mucosa $(\mathbf{a}, \mathbf{d})$, adenoma $(\mathbf{b}, \mathbf{e})$, and carcinoma $(\mathbf{c}, \mathbf{f})(\times 400)$

\section{Discussion}

Carcinomas of the small intestine represent only $1 \%$ of all gastrointestinal malignant tumors but are most common around the papilla of Vater [25-28]. There is good evidence for an adenoma-carcinoma sequence since ampullary carcinomas demonstrate residual adenomatous areas in up to $84 \%$ of cases [29-31]. On the other hand, up to $65 \%$ of 
Table 3 Immunoprofiles of carcinoma subtypes

\begin{tabular}{|c|c|c|c|c|c|c|c|c|}
\hline \multirow[t]{2}{*}{ Protein } & \multirow[t]{2}{*}{ Expression } & \multirow[t]{2}{*}{ Cutoff } & \multicolumn{5}{|c|}{ Histologic type $(N=175)$} & \multirow[t]{2}{*}{$p$ value } \\
\hline & & & IT $N=85$ & IMT $N=16$ & PBT $N=42$ & $\mathrm{G} 3 \mathrm{AC} N=23$ & IPT $N=9$ & \\
\hline \multirow[t]{3}{*}{ CK7 } & & 80 & & & & & & \multirow{3}{*}{$<0.001$} \\
\hline & Negative & & $54(67.5)$ & $12(92.3)$ & $10(26.3)$ & $10(47.6)$ & $3(33.3)$ & \\
\hline & Positive & & $26(32.5)$ & $1(7.7)$ & $28(73.7)$ & $11(52.4)$ & $6(66.7)$ & \\
\hline \multirow[t]{3}{*}{ CK20 } & & 50 & & & & & & \\
\hline & Negative & & $33(41.8)$ & $7(50.0)$ & $19(51.3)$ & $11(52.4)$ & $6(66.7)$ & \multirow[b]{2}{*}{0.588} \\
\hline & Positive & & $46(58.2)$ & $7(50.0)$ & $18(48.7)$ & $10(47.6)$ & $3(33.3)$ & \\
\hline \multirow[t]{3}{*}{ p21 } & & 0 & & & & & & \multirow[b]{3}{*}{0.27} \\
\hline & Negative & & $41(52.6)$ & $7(50.0)$ & $28(71.7)$ & $14(66.7)$ & $6(66.7)$ & \\
\hline & Positive & & $37(47.4)$ & $7(50.0)$ & $11(28.3)$ & $7(33.3)$ & $3(33.3)$ & \\
\hline \multirow[t]{3}{*}{ p27 } & & 5 & & & & & & \multirow[b]{3}{*}{0.012} \\
\hline & Negative & & $32(44.4)$ & $5(45.5)$ & $26(78.8)$ & 7 (38.9) & $5(62.5)$ & \\
\hline & Positive & & $40(55.6)$ & $6(54.6)$ & $7(21.2)$ & $11(61.1)$ & $3(37.5)$ & \\
\hline \multirow[t]{3}{*}{ ESA } & & 90 & & & & & & \multirow[b]{3}{*}{0.038} \\
\hline & Negative & & $31(38.7)$ & $7(50.0)$ & $26(70.3)$ & $10(50.0)$ & $4(44.4)$ & \\
\hline & Positive & & $49(61.3)$ & $7(50.0)$ & $11(19.7)$ & $10(50.0)$ & $5(55.6)$ & \\
\hline \multirow[t]{4}{*}{ bax } & & 10 & & & & & & \multirow{4}{*}{$<0.001$} \\
\hline & Negative & & $29(39.2)$ & $3(25.0)$ & $28(77.8)$ & $13(72.2)$ & $4(44.4)$ & \\
\hline & & & & & & & & \\
\hline & Positive & & $45(60.8)$ & $9(75.0)$ & $8(22.2)$ & $5(27.8)$ & $5(55.6)$ & \\
\hline \multirow[t]{4}{*}{ ephB2 } & & 75 & & & & & & \multirow{4}{*}{0.526} \\
\hline & Negative & & $36(50.0)$ & $9(75.0)$ & $15(46.9)$ & 7 (46.7) & $5(55.6)$ & \\
\hline & & & & & & & & \\
\hline & Positive & & $36(50.0)$ & $3(25.0)$ & $17(53.1)$ & $8(53.3)$ & $4(44.4)$ & \\
\hline
\end{tabular}

patients suffering from adenoma were shown to have coexisting carcinoma [32]. Ampullary carcinomas are heterogeneous in terms of their histomorphological differentiation, probably due to the distinct epithelial subtypes adjoining in the ampulla of Vater [16-18]. In our series, IT ( 85 of $175,49 \%$ ) and PBT (42 of 175, 24\%) were the most common subtypes, followed by G3AC (23 of $175,13 \%)$, IMT (16 of 175, 9\%), and IPT (nine of 175, 5\%). This is in line with most of the reported series in the literature with only some smaller studies demonstrating PBT to be more common than IT $[5,6,16-18,20,21]$. Importantly, the distinct histologic subtypes were shown to exhibit significant differences in clinical outcome, with IT and IMT demonstrating a favorable prognosis [cumulative survival (CS) 97 and 76 months] compared to IPT, PBT, and G3AC (CS 59, 41, and 19 months; Ruemmele et al., submitted for publication). The favorable prognosis of IT compared to PBT has previously been shown in several studies $[16,17$, 20]. During staging procedures in patients with ampullary tumors, pathologists generally receive endoscopically obtained biopsies that can be difficult to interpret and to classify on histomorphological criteria alone. Our study therefore aimed to delineate immunohistochemical and genomic profiles of the distinct carcinoma subtypes using FISH analyses and an immunohistochemical panel of common marker proteins.

Carcinoma, adenoma, and normal ampullary mucosa samples demonstrated statistically significant differences in the expression of CK7 and bax. Whereas CK7 expression increased from normal to malignant tissue samples, bax expression decreased in the same manner. The remaining protein markers, particularly p27, also revealed significant differences in their expression values between the three groups but not as unequivocally as CK7 and bax. Concerning the histologic subtypes of ampullary carcinomas, the expression levels of CK7, p27, ESA, and bax demonstrated the most distinctive results. Whereas more than $75 \%$ of PBT and $72.2 \%$ of G3AC were negative for bax, IMT was negative for CK7 in $92 \%$ of cases. Accordingly, multivariable analysis showed lack of CK7 

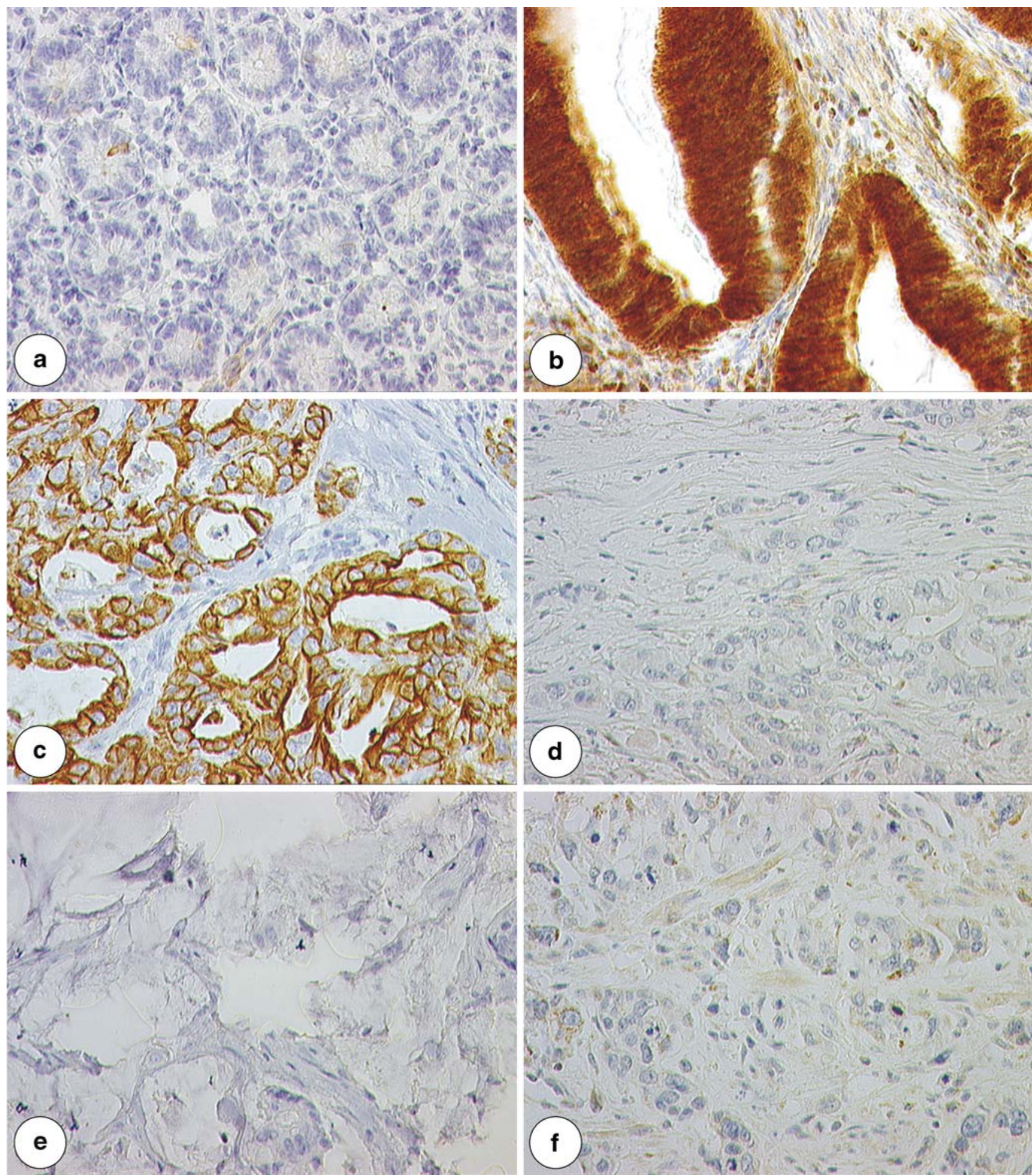

Fig. 3 Immunostaining of CK7 in IT (a), bax in IT (b), CK7 in PBT (c), bax in PBT (d), CK7 in IMT (e), and bax in G3AC (f) $(\times 400)$

to be strongly predictive for IMT, whereas CK7 positivity and negativity for bax, p27, and ESA were significantly associated with PBT. Expression of CK7 was rather uncommon in IT $(32.5 \%)$. Multivariable analysis consis- tently demonstrated CK7 negativity and positivity for $\mathrm{p} 27$, ESA, and bax to be strongly correlated with IT. IPT represented the rarest subtype in our series, and therefore, only limited conclusions can be drawn concerning a 


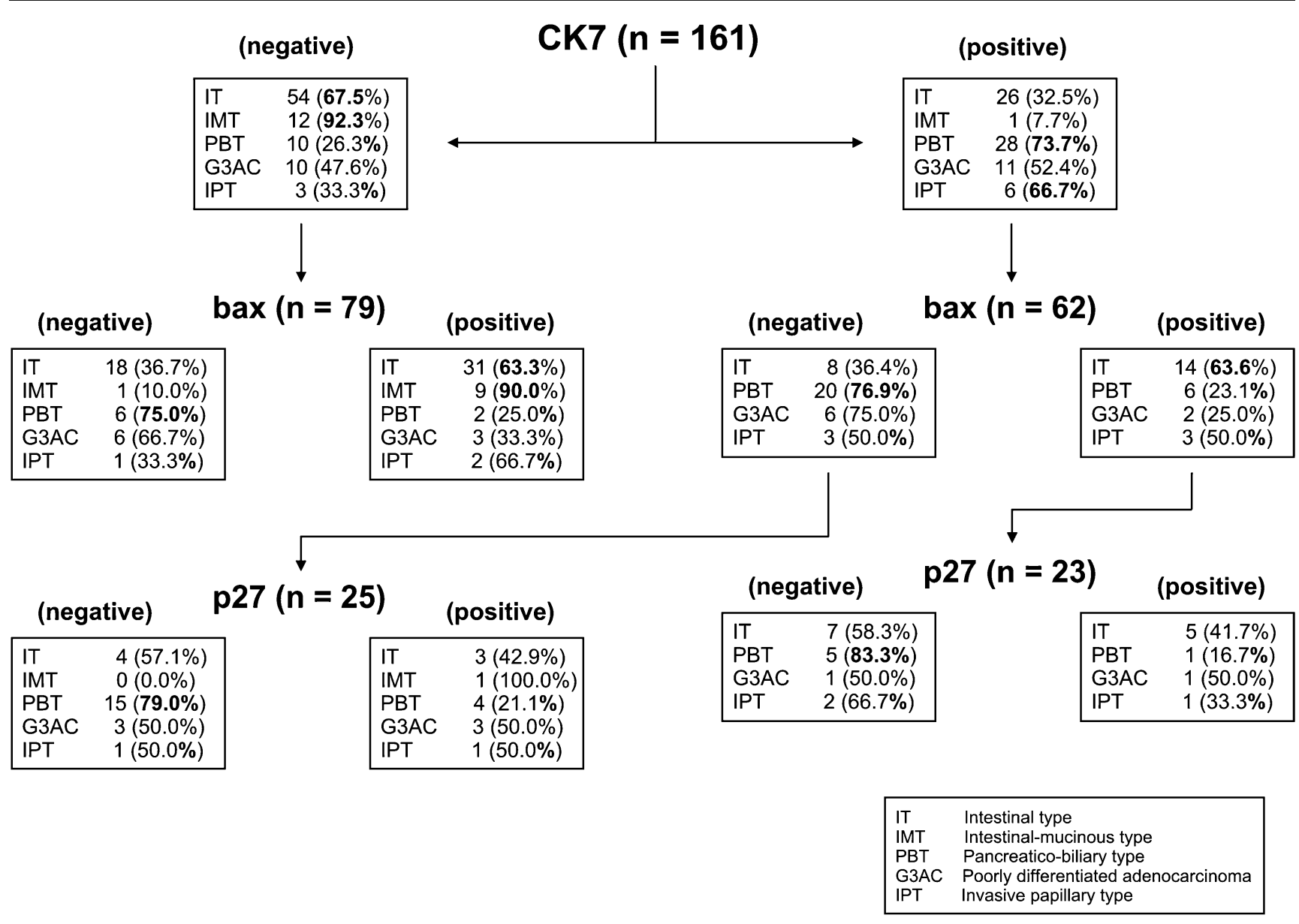

Fig. 4 Flow chart demonstrating immunoprofiles of carcinoma subtypes

representative immunoprofile. Nevertheless, IPT tended to stain positive for $\mathrm{CK} 7$ and negative for p27 in most of the investigated cases.

FISH analyses demonstrated amplification of c-myc, EGFR1, CCND1, and HER2 only infrequently with no obvious correlations to carcinoma subtypes. From all investigated oncogenes, CCND1 showed the highest amplification frequency in our series (two of 74 adenomas and ten of 134 carcinomas). The CCND1 gene is coding for a cyclin which is known to be translocated, amplified, and overexpressed in many different tumor types including mantle cell lymphoma, head and neck carcinoma, breast carcinoma, hepatocellular carcinoma, gastrointestinal stromal tumors, and various sarcomas [33-36]. Since CCND1 has been shown to be essential for malignant transformation of epithelial cells, it could play an important role in tumorigenesis in a distinct subset of ampullary carcinomas. C-myc, that we demonstrated only recently to be amplified in up to $14.2 \%$ of colorectal carcinomas, showed no amplification in any of the ampullary carcinomas investigated [37]. Whereas EGFR was only amplified in one case, HER2 showed amplification in $6 \%$ of adenomas and carcinomas (two IT, two IPT, one G3AC). A small fraction of patients with ampullary carcinomas could therefore be candidates for a targeted therapy with Herceptin.

Taken together, accurate classification of ampullary carcinomas is of crucial importance since the distinct

Table 4 Amplification of oncogenes

\begin{tabular}{llll}
\hline Oncogene & \multicolumn{2}{l}{ Amplification } & \\
\cline { 2 - 4 } & Normal & Adenoma & Carcinoma \\
\hline c-myc & $N=26$ & $N=36$ & $N=70$ \\
& $0 / 26$ & $1 / 36$ & $0 / 70$ \\
EGFR & $N=83$ & $N=79$ & $N=137$ \\
& $0 / 83$ & $1 / 79$ & $1 / 137^{\mathrm{a}}$ \\
CCND1 & $N=88$ & $N=74$ & $N=134$ \\
HER2 & $0 / 88$ & $2 / 74$ & $10 / 134^{\mathrm{b}}$ \\
& $N=46$ & $N=45$ & $N=82$ \\
& $0 / 46$ & $3 / 45$ & $5 / 82^{\mathrm{c}}$ \\
\hline
\end{tabular}

${ }^{\mathrm{a}}$ One IT

${ }^{\mathrm{b}}$ Six IT, two PBT, one G3AC, one IPT

${ }^{\mathrm{c}}$ Two IT, one G3AC, two IPT 
subtypes were shown to differ significantly in clinical outcome. Using an immunohistochemical panel of established marker proteins including CK7, p27, ESA, and bax can improve and facilitate differential diagnosis, especially in small and fragmented biopsy samples. A subset of ampullary tumors, furthermore, shows amplification of CCND1 and HER2 which could represent potential targets for cancer therapy. The large number of tumors included in this study highlights the presence of rare molecular events that can be of potential therapeutic relevance.

Conflict of interest statement We declare that we have no conflict of interest.

\section{References}

1. Allescher HD (1989) Papilla of Vater: structure and function. Endoscopy 21(Suppl 1):324-329

2. Neoptolemos JP, Talbot IC, Carr-Locke DL et al (1987) Treatment and outcome in 52 consecutive cases of ampullary carcinoma. Br J Surg 74:957-961

3. Albores-Saavedra J, Scoazec JC, Wittekind C et al (2000) Tumours of the gallbladder and extrahepatic bile ducts. In: Hamilton SR, Aaltonen LA (eds) World Health Organization classification of tumours: pathology and genetics of tumours of the digestive system. IARC, Lyon, pp 203-218

4. Wright NH, Howe JR, Rossini FP et al (2000) Tumours of the small intestine. In: Hamilton SR, Aaltonen LA (eds) World Health Organization classification of tumours: pathology and genetics of tumours of the digestive system. IARC, Lyon, pp 69-92

5. Fischer HP, Zhou H (2004) Pathogenesis of carcinoma of the papilla of Vater. J Hepatobiliary Pancreat Surg 11:301-309

6. Howe JR, Klimstra DS, Moccia RD et al (1998) Factors predictive of survival in ampullary carcinoma. Ann Surg 228:87-94

7. Kaiser A, Jurowich C, Schonekas H et al (2002) The adenomacarcinoma sequence applies to epithelial tumours of the papilla of Vater. Z Gastroenterol 40:913-920

8. Takashima M, Ueki T, Nagai E et al (2000) Carcinoma of the ampulla of Vater associated with or without adenoma: a clinicopathologic analysis of 198 cases with reference to p53 and Ki-67 immunohistochemical expressions. Mod Pathol 13:1300-1307

9. Todoroki T, Koike N, Morishita Y et al (2003) Patterns and predictors of failure after curative resections of carcinoma of the ampulla of Vater. Ann Surg Oncol 10:1176-1183

10. Bouvet M, Gamagami RA, Gilpin EA et al (2000) Factors influencing survival after resection for periampullary neoplasms. Am J Surg 180:13-17

11. Chang MC, Chang YT, Tien YW et al (2005) Distinct chromosomal aberrations of ampulla of Vater and pancreatic head cancers detected by laser capture microdissection and comparative genomic hybridization. Oncol Rep 14:867-872

12. Yeo CJ, Cameron JL, Sohn TA et al (1997) Six hundred fifty consecutive pancreaticoduodenectomies in the 1990s: pathology, complications, and outcomes. Ann Surg 226:248-257; discussion $57-60$

13. Di Giorgio A, Alfieri S, Rotondi F et al (2005) Pancreatoduodenectomy for tumors of Vater's ampulla: report on 94 consecutive patients. World J Surg 29:513-518

14. Sperti C, Pasquali C, Piccoli A et al (1994) Radical resection for ampullary carcinoma: long-term results. Br J Surg 81:668-671
15. Talamini MA, Moesinger RC, Pitt HA et al (1997) Adenocarcinoma of the ampulla of Vater. A 28-year experience. Ann Surg 225:590-599; discussion 9-600

16. Beghelli S, Orlandini S, Moore PS et al (2002) Ampulla of vater cancers: T-stage and histological subtype but not Dpc4 expression predict prognosis. Virchows Arch 441:19-24

17. Westgaard A, Tafjord S, Farstad IN et al (2008) Pancreatobiliary versus intestinal histologic type of differentiation is an independent prognostic factor in resected periampullary adenocarcinoma. BMC Cancer 8:170

18. Albores-Saavedra J, Henson DE, Klimstra DS (2000) Tumors of the gallbladder, extrahepatic bile ducts, and ampulla of Vater. Armed Forces Institute of Pathology, Washington, DC

19. Fischer HP, Zhou H (2003) [Pathogenesis and histomorphology of ampullary carcinomas and their precursor lesions. Review and individual findings]. Pathologe 24:196-203

20. Kimura W, Futakawa N, Yamagata S et al (1994) Different clinicopathologic findings in two histologic types of carcinoma of papilla of Vater. Jpn J Cancer Res 85:161-166

21. Matsubayashi H, Watanabe H, Yamaguchi T et al (1999) Differences in mucus and K-ras mutation in relation to phenotypes of tumors of the papilla of vater. Cancer 86:596-607

22. Zlobec I, Minoo P, Baker K et al (2007) Loss of APAF-1 expression is associated with tumour progression and adverse prognosis in colorectal cancer. Eur J Cancer 43:1101-1107

23. Zlobec I, Vuong T, Hayashi S et al (2007) A simple and reproducible scoring system for EGFR in colorectal cancer: application to prognosis and prediction of response to preoperative brachytherapy. Br J Cancer 96:793-800

24. Zlobec I, Lugli A (2008) Prognostic and predictive factors in colorectal cancer. A critical review. J Clin Pathol 61:561-569

25. Barclay TH, Schapira DV (1983) Malignant tumors of the small intestine. Cancer 51:878-881

26. Santoro E, Sacchi M, Scutari F et al (1997) Primary adenocarcinoma of the duodenum: treatment and survival in 89 patients. Hepatogastroenterology 44:1157-1163

27. Thomas RM, Sobin LH (1995) Gastrointestinal cancer. Cancer $75: 154-170$

28. Weiss NS, Yang CP (1987) Incidence of histologic types of cancer of the small intestine. J Natl Cancer Inst 78:653-656

29. Kozuka S, Tsubone M, Yamaguchi A et al (1981) Adenomatous residue in cancerous papilla of Vater. Gut 22:1031-1034

30. Perzin KH, Bridge MF (1982) Adenomatous and carcinomatous changes in hamartomatous polyps of the small intestine (PeutzJeghers syndrome): report of a case and review of the literature. Cancer 49:971-983

31. Sellner F (1990) Investigations on the significance of the adenomacarcinoma sequence in the small bowel. Cancer 66:702-715

32. Perzin KH, Bridge MF (1981) Adenomas of the small intestine: a clinicopathologic review of 51 cases and a study of their relationship to carcinoma. Cancer 48:799-819

33. Fritz B, Schubert F, Wrobel G et al (2002) Microarray-based copy number and expression profiling in dedifferentiated and pleomorphic liposarcoma. Cancer Res 62:2993-2998

34. Hall M, Peters G (1996) Genetic alterations of cyclins, cyclindependent kinases, and $\mathrm{Cdk}$ inhibitors in human cancer. Adv Cancer Res 68:67-108

35. Kim SH, Lewis JJ, Brennan MF et al (1998) Overexpression of cyclin D1 is associated with poor prognosis in extremity softtissue sarcomas. Clin Cancer Res 4:2377-2382

36. Tornillo L, Duchini G, Carafa V et al (2005) Patterns of gene amplification in gastrointestinal stromal tumors (GIST). Lab Invest 85:921-931

37. Al-Kuraya K, Novotny H, Bavi P et al (2007) HER2, TOP2A, CCND1, EGFR and C-MYC oncogene amplification in colorectal cancer. J Clin Pathol 60:768-772 